\title{
Striatal Cell Grafts in Infarcted Striatum After Occlusion of the Middle Cerebral Artery Improve Behavioral, Chemical and Receptor Deficits in the Rat
}

\author{
H. Nishino, T. Hashitani, K. Koide ${ }^{1}$, N. Aihara ${ }^{1}$, K. Mizukawa ${ }^{2}$ and H. Nagai ${ }^{1}$ \\ Departments of Physiology and ${ }^{1}$ Neurosurgery, Nagoya City University Medical School, Mizuho-ku, Nagoya \\ 467 and ${ }^{2}$ Department of Anatomy, Okayama University Medical School, Okayama 700, Japan
}

Fetal striatal cell suspensions were grafted in infarcted striata of adult (300-400 g) rats after occlusion of the middle cerebral artery (MCA). The survival/development of grafted cells, GABA release, $\mathrm{GABA}_{\mathrm{A}}$ receptor binding and behavioral recovery were investigated. Under halothane anesthesia a silicon-coated plug was inserted intraluminally from the external artery to the brain via the carotid communical artery and the circle of Willis. The plug was set at the origin of the MCA (about $15 \mathrm{~mm}$ from the carotid bifurcation) to occlude the blood flow to the artery and anesthesia was cut off (i.e., ischemia without anesthesia). One hour later, the animal was again anesthetized by halothane and the plug was withdrawn. Motor deficits such as hemiparesis and rotation appeared during and shortly after the ischemia but no motor deficits were observed after 3 days. The occlusion primarily induced ischemic infarcts in the lateral striatum and adjacent cortex, but the size of the infarcts was variable. Infarcted rats showed deficits in a passive avoidance task. The total time of electrical shock (TTES) the rats received during a 5 min test period over 6 consecutive days of the passive avoidance training was used as a parameter to assess learning. In control rats, TTES decreased day by day and stabilized at a low level (5 to $10 \mathrm{sec}$ ) after the 6th day of training. In infarcted rats, the TTES was significantly greater than that of controls and did not decrease. In the 2nd series of the test (one month inter-test interval), TTES remained low in control rats, suggesting that the retention as well as the acquisition of learning was excellent. In infarcted rats both acquisition and retention were disturbed. In infarcted animals the GABA level in the globus pallidus, detected by microdialysis and HPLC analysis, decreased to about a half of that of the controls. Transplantation was performed at 2 to 5 weeks after the ischemia. Fetal striatal cell suspensions were injected stereotaxically into the infarcted striatum. After the graft, TTES in infarcted-grafted rats decreased with training as in control rats. Choline acetyltransferase-positive and GABA-positive cells survived in the grafts. The GABA level recovered moderately, and increased further with infusion of nipecotic acid (GABA uptake blocker). An autoradiographic binding study using ${ }^{3} \mathrm{H}$-labeled agonists and antagonists revealed that muscarinic, D1, D2 as well as $\mathrm{GABA}_{\mathrm{A}}$ receptors were expressed in the grafts.

These data indicate that fetal striatal cell grafts in the infarcted striatum partially improve behavioral deficits with a concomitant reorganization of cytoarchitecture.

Supported by Grant-in-Aid for Scientific Research 03454133 and Developmental Scientific Research 04557005. 

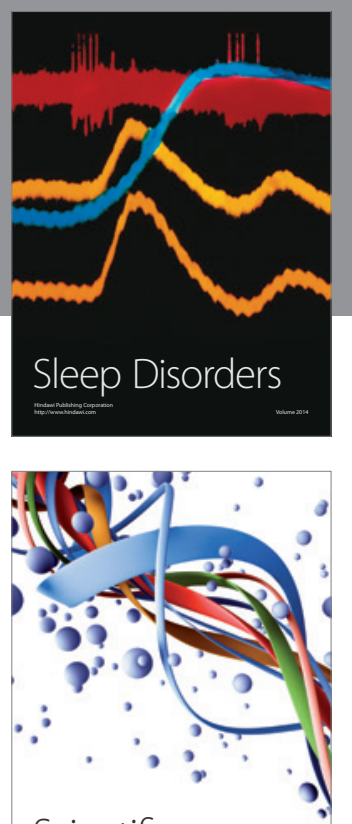

Scientifica
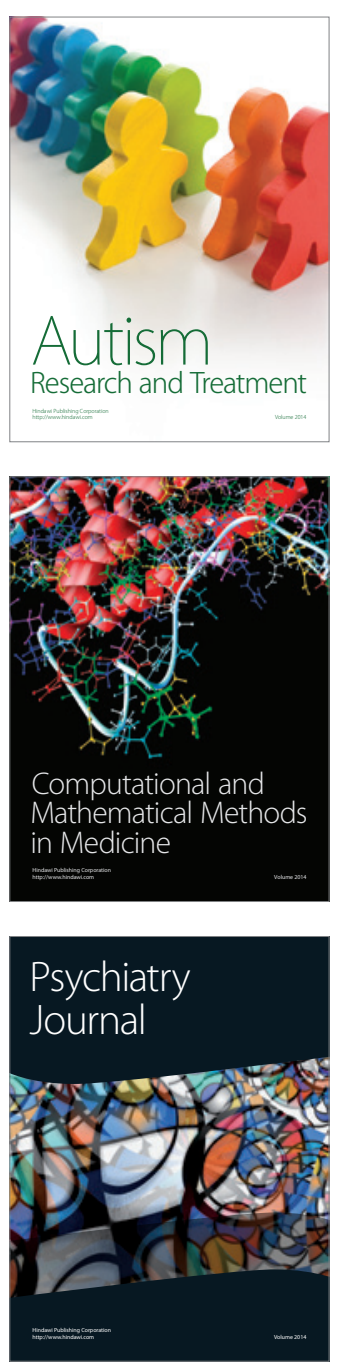
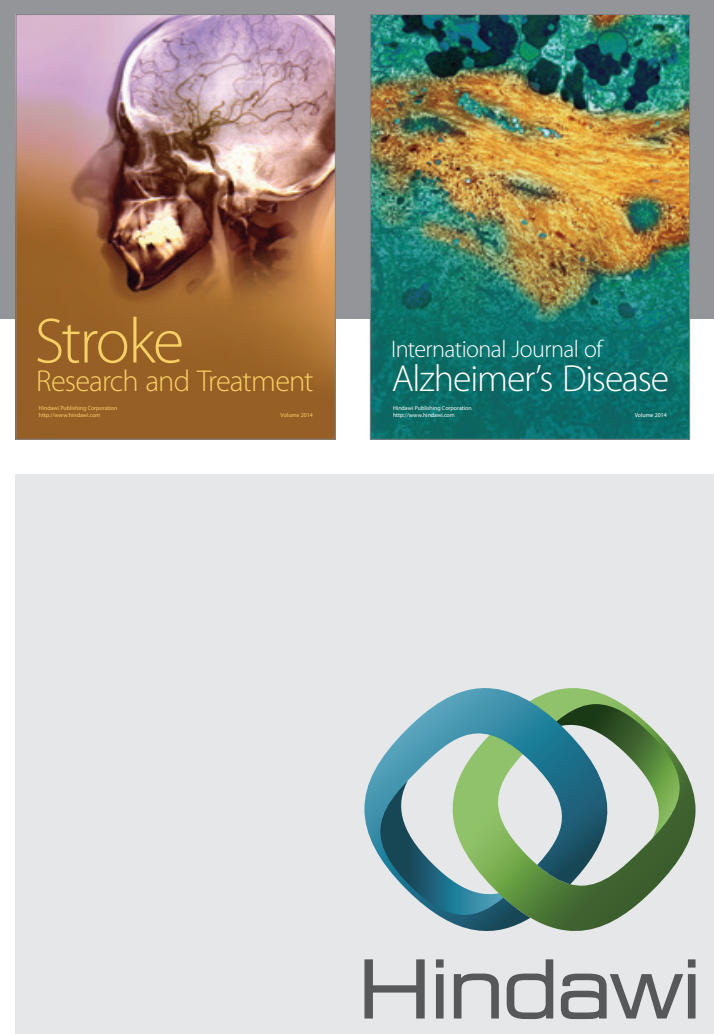

Submit your manuscripts at

http://www.hindawi.com
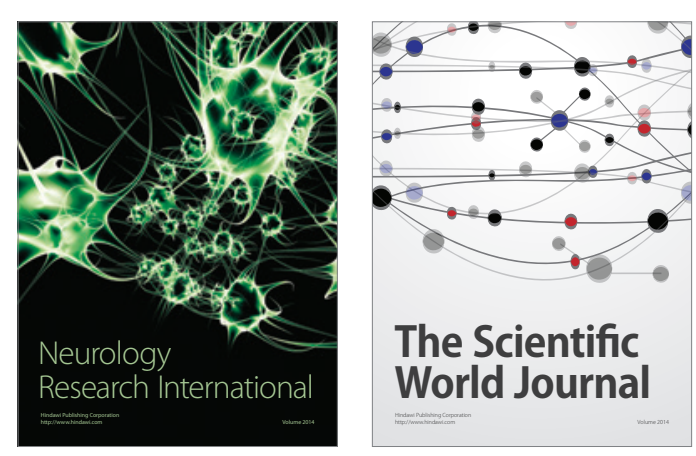

The Scientific World Journal

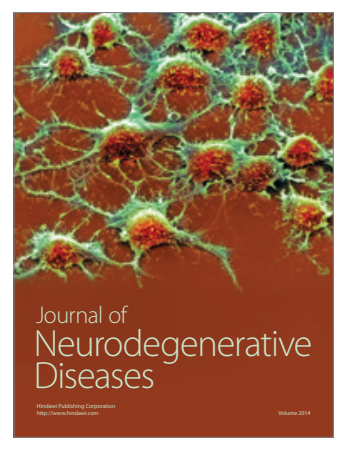

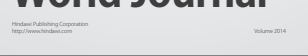

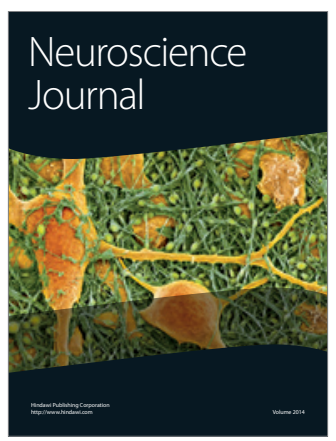

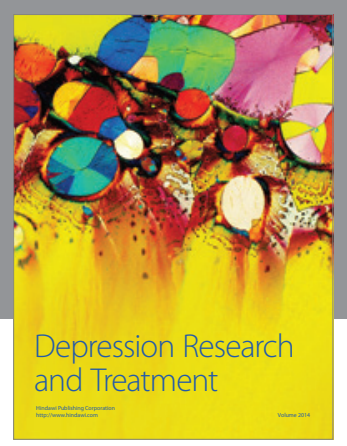
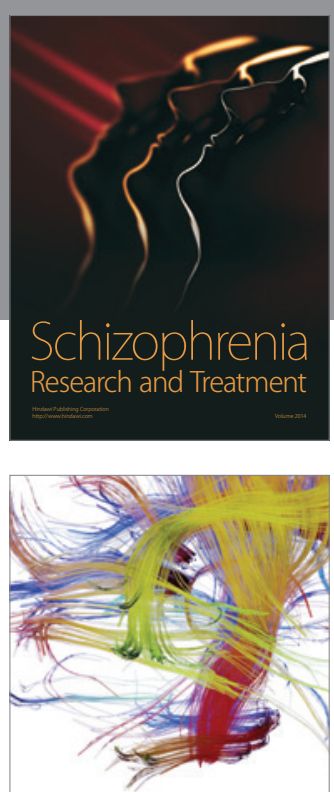

Brain Science

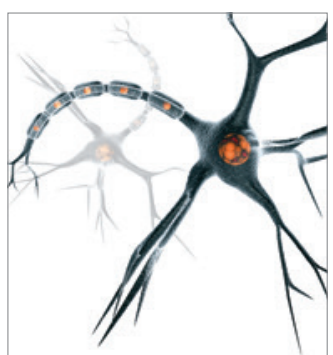

Neural Plasticity
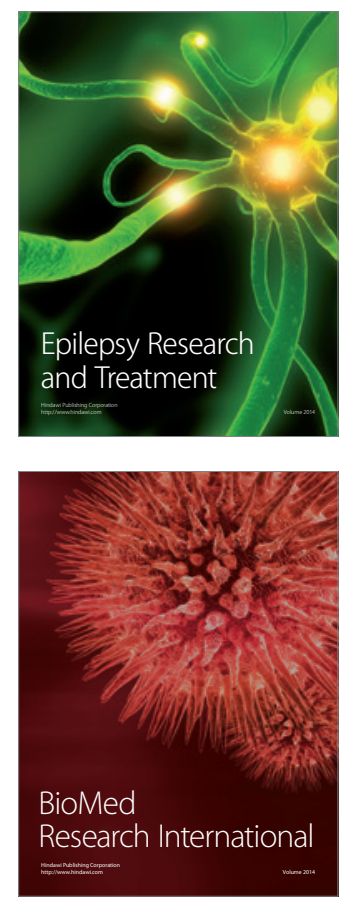

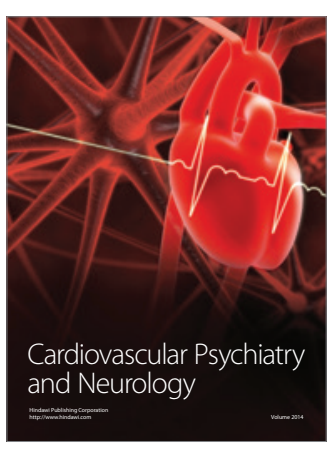

Parkinson's

Disease
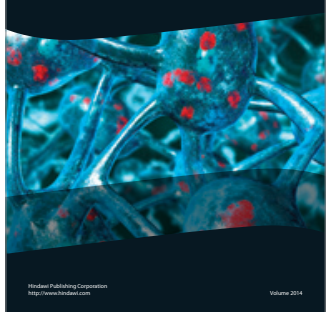